\title{
EVALUATION OF CONSERVATIVE MANAGEMENT OF CONGENITAL NASOLACRIMAL DUCT OBSTRUCTION IN INFANTS BETWEEN 2WKS TO 11 MONTHS AGE.
}

P. Sudhir Babu, Arvind Ram, G. Amaresh

1. Associate Professor. Department of Ophthalmology, Kamineni Institute of Medical Sciences, Narketpally.

2. Assistant Professor. Department of Ophthalmology, Kamineni Institute of Medical Sciences, Narketpally.

3. Professor \& HOD. Department of Ophthalmology, Kamineni Institute of Medical Sciences, Narketpally.

\section{CORRESPONDING AUTHOR}

Dr .P. Sudhir Babu,

Associate Professor, Dept of Ophthalmology,

Kamineni Institute of Medical Sciences,

Narketpally, Nalagonda dist Andhra Pradesh,

E-mail: spadgul@gmail.com

Ph: 00919701896996

ABSTR ACT: BACKGROUND: Congenital nasolacrimal duct obstruction is a condition with non canalisation of the membranous part of the duct at the level of valve of Hasner and occurs in 5$6 \%$ of infants, Nasolacrimal duct massaging is a standard procedure which increases the hydrostatic pressure in the canal thus widening and opening the canal at the level of valve of Hasner. STUDY DESIGN: This was a prospective study conducted to determine the efficacy of nasolacrimal duct massaging in infants with congenital nasolacrimal duct obstruction. Infants presenting with discharge and duct obstruction were included in the study. Parents were demonstrated and made to do the nasolacrimal duct massaging. All cases were reviewed at $4^{\text {th }}$, $6^{\text {th }}, 8^{\text {th }}, 12^{\text {th }}, 16^{\text {th }}$ weeks and changes in the symptoms were recorded. Time at which there was no discharge was considered to be cured. RESULTS: Out of 57 cases, 35(61.40\%) were males and $22(38.59 \%)$ were females. 11 cases had bilateral presentation and 46 eyes had unilateral presentation (26 RE,20 LE). Mean and standard deviation of age of presentation was 2 months 27 days (87.127 \pm 41.147 days). Median age of presentation was 95 days and Mode was 115 days. Mucoid discharge 24(42.10\%)and mucopurulent discharge 20 (35.08\%) were the most common presenting symptoms. 52.63\% were referred by Paediatric department. Out of 57 cases $50(87.71 \%)$ responded to NLD massaging, 5(8.77\%) cases responded to probing. 2 cases were referred to oculoplasty surgeon. Success rate of Combined nasolacrimal duct obstruction massaging and probing was 96.49\% CONCLUSION: With this study we conclude that, conservative management of cases with congenital nasolacrimal duct obstruction has good results when in early infancy. Proper education of parents or relatives and proper understanding of the massaging process is must.

KEY WORDS: Congenital, Nasolacrimal duct, Massaging, Probing.

INTRODUCTION: Congenital nasolacrimal duct obstruction also known as dacryostenosis ${ }^{1}$ is seen in $5 \%$ of the infants, percentage is higher in premature infants. Presents in the first few months of life and resolves completely by the end of 1 st year with conservative management.

In congenital nasolacrimal duct obstruction block is at lower membranous part and valve of Hasner. It manifests by third week of life. ${ }^{9}$ common manifestations are Epiphora, Mucoid or Mucopurulent discharge. Conservative management of nasolacrimal duct massaging increases the hydrostatic pressure in the canal and clears the block in $90 \%$ of the cases. There 
is high rate of resolution in first year of life.3,4 Parents bring the child with complaints of watering, discharge. Cases are usually referred to an ophthalmologist when conservative treatment with antibiotic drops fail. These cases usually respond to the Nasolacrimal Duct massaging provided done with proper technique and frequency, consistently. Cases which fail to respond to Nasolacrimal Duct massaging respond to probing, this is a minor procedure which releases the resistance of the flow at the lower end of the duct? ${ }^{7}$. Most common cause of failure of nasolacrimal duct massaging is improper technique, and inadequate frequency. ${ }^{11}$

METHOD OF NASOLACRIMAL DUCT MASSAGING 1, 11: This is done by applying moderate pressure over the medial part of the medial canthus blocking the common canalicular duct and creating a pressure in the sac, the stroke is then taken down sliding the finger down towards the bridge of the nose so that the hydrostatic pressure created is passed down to the lower part of the membranous duct and valve of the Hasner. Frequency of massaging is 5-10 strokes per set and 3-4 sets per day. It is advisable to apply ointment to the finger so that waxy base acts as a lubricant and does not irritate infant's skin. Mothers are advised to keep their finger nails trimmed. Index finger is commonly used to have control over the pressure and direction of the stroke. Proper demonstration of the procedure to parents and make them repeat in front of ophthalmologist.

ANATOMY OF THE NASOLACRIMAL DUCT: Nasolacrimal duct is the passage through which the tears from the eye are drained down to the inferior meatus. It consists of two parts superior intra osseous part measuring $12-\mathrm{mm}$, and inferior membranous part measuring $5-\mathrm{mm}$. The bony nasolacrimal canal is approximately $1 \mathrm{~mm}$ in diameter; the intraosseous part is directed downwards and postero laterally through the maxillary bone, while the membranous part runs within the nasal mucosa, eventually opening into the inferior meatus under the inferior nasal turbinate. ${ }^{6}$

Duct is guarded by a membranous valve known as valve of Hasner at the opening in the inferior meatus, nature has created this valve to prevent nasal secretions entering into the eye which is a potential source of infection. ${ }^{12}$ The valve of Hasner, at the opening of the nasolacrimal duct within the nasal cavity, has been found to be imperforate in up to $70 \%$ of newborns. Spontaneous opening of an imperforate valve of Hasner usually occurs within first month of life , failure of this valve to open or improper canalisation of the membranous part of the nasolacrimal duct will cause congenital nasolacrimal duct obstruction and presents with watering.

PRESENTATION: Infants with congenital nasolacrimal duct obstructions present with either epiphora, sticky mucoid or mucopurulent discharge. ${ }^{1,13}$ In some cases child is brought to an ophthalmologist with complaints of tears standing in the eye even when child is not crying this is referred to as tear lake. There may be matting of lashes and purulent discharge if associated with secondary infection.

MANAGEMENT: Management of congenital nasolacrimal duct obstruction includes a). Conservative nasolacrimal duct massaging. b) Probing c.) Intubation d) Balloon Catheter Dilation e) Dacryocystorhinostomy. 80-90\% of the cases respond to conservative massaging of the nasolacrimal duct done in a proper way, non resolving cases may require probing which can be repeated maximum upto 3 times, which gives $100 \%$ results. ${ }^{1}$ If watering persists even after 
probing then anatomical defect in the Nasolacrimal Duct should be suspected and these cases need thorough evaluation including Dacryocystography , CT. and those cases may need surgical intervention.

\section{DIFFERENTIAL DIAGNOSIS:}

Epiphora in infants requires a detail check up to rule out other causes of watering and discharge. Common cause which need to be ruled out are:

- Ophthalmia Neonatorum

- Congenital Glaucoma

- Ocular Foreign Body

- Corneal Abrasion

- Birth trauma

- Keratitis

\section{MATERIALS AND METHODS:}

\section{CASE SELECTION:}

\section{INCLUSION CRITERIEA:}

- All cases with history of watering and discharge between the age of 2 weeks to 8 months.

\section{EXCLUSION CRITERIA}

- Infants less than 2 weeks.

- Corneal abrasion

- Birth trauma

- Congenital glaucoma

- Keratitis

This was a prospective study conducted at the Department of Ophthalmology KIMS Narketpally, between Jan 2012 to Dec 2012. Purpose of the study was to evaluate the efficacy of conservative management Nasolacrimal Duct Massaging in cases of congenital nasolacrimal duct obstruction. After confirming the congenital nasolacrimal duct obstruction by fluoroscein dye disappearance test. Parents were explained the standard course of the treatment of the condition and informed consent was taken from the parents for enrollment into the study and follow up. Out of 65 cases enrolled for the study 8 cases dropped out during follow up and finally 57 cases were taken up for the study. Detailed history regarding presenting complaints, duration of the present illness, family history, socioeconomic status, previous treatment if any was taken and recorded. History of presenting complaints with respect to type of discharge and epiphora was taken and recorded.

Complete ocular examination of the infant was done to rule out other ophthalmic abnormalities, infants with other ocular diseases or anomalies like congenital glaucoma, birth trauma, Ophthalmia Neonatorum were not included in the study. Fluoroscein Dye Disappearance test was done all cases to confirm nasolacrimal duct obstruction.

Infant's parents particularly mothers were demonstrated the correct method of nasolacrimal duct massaging, and made to understand the importance of the procedure and any doubts regarding the procedure conditions were clarified. Mother was again made to perform nasolacrimal duct massaging in front of the ophthalmologist to ascertain the correct technique and understanding level of the mother. Parents were prescribed antibiotic ointment and drops 
to be applied to the affected eye. Parents were advised to apply antibiotic ointment to the index figure before massaging as its waxy base acts as lubricant and avoids skin irritation. After proper instructions patients were followed up on $4^{\text {th }}, 6$ th $8^{\text {th }} 12^{\text {th }}$ and $16^{\text {th }}$ week and findings recorded.

OBSERVATION AND RESULTS: Gender Distribution: Out of 57 cases 35 (61.40\%) were Males and 22 (38.59\%) were Females (Figure.1). Laterality: 26 (45.61\%) cases Right Eye was involved, in 20 (35.08\%) cases Left Eye was involved. 11(19.29\%) cases had Bilateral involvement.(Figure.2). Measures of Central Tendency: Mean age of presentation was 2 months 27 days ( $87.127 \pm 41.147$ days). Median age of presentation was 95 days. Mode of the age was 115 days. Presentation Pattern: 13 (22.80\%) infants presented with Epiphora , 24 (42.10\% )infants presented with Mucopurulent discharge and 20(35.08\%) infants had Mucoid discharge.(Table.1) Socio Economic Status:19 (33.33\%) infants belonged to Poor socio economic strata. 21( $36.84 \%$ ) patients were from Middle socio economic strata and 17(29.82\%) patients belonged to Higher socioeconomic strata. Referral Pattern: 30(53\%) patients were referred by paediatricians after initial antibiotics drops , 22(38\%) patients were brought by their parents on their own. 5(9\%) patients were referred by Registered Medical Practitioners. Conservative Management: 44(77.19\%) infants were relieved of symptoms after conservative treatment for 8-12 weeks with progressive reduction of symptoms from $4^{\text {th }}$ week onwards. 13 infants had no change in symptoms on $6^{\text {th }}$ week of follow up, on careful interrogation it was found that in 6 infants, massaging had not been done in proper technique as demonstrated to them initially. In all of these cases massaging was restarted after demonstration of proper technique and 6 were relieved of symptoms by the end of $16^{\text {th }}$ week. Total outcome of conservative nasolacrimal duct massaging was 50(44+6) $87.71 \% .7$ cases had to be taken up for probing after the age of 8 months out of which 3 were cured after $1^{\text {st }}$ probing and 2 were relieved of symptoms after $2^{\text {nd }}$ probing .2 cases did not respond to repeated probing. Out of 57 patients involved into the study 55 (96.49\%) cases responded to combined nasolacrimal duct massaging and probing.

DISCUSSION: Congenital nasolacrimal duct obstruction occurs in 5-6\% of infants. It is a benign condition which responds to nasolacrimal duct massaging in $90 \%$ of cases. Proper technique of massage is important for good results. Importance of nasolacrimal duct massage was duct was demonstrated by Crigler $^{3}(1923)$. Price ${ }^{4}(1942)$ demonstrate the importance of nasolacrimal duct massage with success rate of $94 \%$ Gender: In our study $61 \%$ were Male and $39 \%$ were Females Nazaullah khan et al(2006) ${ }^{13}$ reported $64 \%$ male and $36 \%$ female distribution. Halipota et al reported that $65 \%$ of cases were male and $35 \%$ female. Laterality: $81 \%$ cases had unilateral presentation, while $19 \%$ had bilateral presentation out of which $46 \%$ cases Right Eye was involved and 35\% cases Left Eye was involved. Bilateral involvement was seen in 19\% of cases, similar results were seen in study done by Nazaullah Khan et al (2006) 20 (80\%) cases were having unilateral involvement and 5 (20\%) cases had bilateral Nasolacrimal Duct block. Right eye was involved in 16 (53.3\%) cases and left eye in 14 (46.7\%) cases. Halipota et al $(2000)^{14}$ reported $71 \%$ cases as unilateral and $29 \%$ cases as Bilateral. Yasuhiro Takahashi et al $(2010)^{18}$ in his study reported $14.0-33.8 \%$ of cases to be bilateral. Socioeconomic Strata: Congenital Nasolacrimal Duct is distributed more in poor socio economic group $33.33 \%$ and middle socio economic group 36.84\% incidence of congenital nasolacrimal duct obstruction could be more in poor and middle socioeconomic group as this was a hospital based study and 
most of the cases are either not reported are left untreated because of ignorance and poverty. Referral: $53 \%$ of the cases were referred by paediatrics department as they were the first to be approached by the parents for presenting complaints. 4 (7.07\%) cases had their siblings affected during their infancy. Clear cut pattern of inheritance of congenital nasolacrimal duct obstruction in healthy is not yet established. This could be a coincidental finding in our study.

Measure Of Central Tendency: Mean age at presentation was 2 Months 27 Days (87.12 days) \pm 41.147 SD which was quiet similar to study done by D. Shivpuri et al(1994) ${ }^{11}$ with mean age at presentation 2 months and 7 days, in group A and 2months 21 days in group B where both groups were subjected for nasolacrimal duct massage with different techniques. Presentation: 22.80\% patients presented with Epiphora and 77.2\% presented with Mucopurulent $(42.10 \%)$ and Mucoid (35.08\%) discharge. Nazaullah Khan et al(2006) ${ }^{13}$ reported $14.8 \%$ cases with Epiphora and 69 (85.2\%) cases with watering with purulent discharge. Success Rate: of nasolacrimal duct massaging in our study was $89.47 \%$. Maximum cases resolved after 8-12 week of nasolacrimal duct massaging. 13 infants had no change in symptoms at $6^{\text {th }}$ week follow up, on careful interrogation it was found that in 6 infants massaging had not been done in proper technique as demonstrated to them initially, in terms of frequency and method. Most of the mothers demonstrated wrong method, some were too gentle. Some were doing less frequently and inconsistently. When re instated for treatment all 6 were relieved of symptoms by the end of $16^{\text {th }}$ week. D. Shivpuri et al(1994) ${ }^{11}$ reported success rate of $91 \%$ in group B patients which was taught proper technique of nasolacrimal duct massaging. Nazaullah khan et al (2006) ${ }^{13}$ who reported success rate of $83.2 \%$. Study done by QasemHammory et al(2010) ${ }^{19}$ reportedsuccess rate of 82.5\%.In another study reported in Arch Ophthalmol. 2012;130(6):730-734. ${ }^{1588 \%}$ of cases with NLDO had resolved without surgery. Probing: 7 cases who did not respond to nasolacrimal duct massaging were taken up for probing out of which 3 responded in first probing and 2 responded on second probing . 2 cases did not respond to either nasolacrimal duct massaging or probing. These were the cases who presented late and started massaging late. Non resolving cases were referred to oculoplasty surgeon for further evaluation and management. over all combined success rate of nasolacrimal duct massaging and probing in our study was $96.49 \%$. NazaullahKhanetal (2006) ${ }^{13}$ reported $100 \%$ success rate after $3^{\text {rd }}$ probing .Kapadiaetal (2006) ${ }^{17}$ overall success rate was $72 \%$. Children aged $<36$ months had a success rate of $78 \%$; children aged $\geq 36$ months had a success rate of $50 \%$. They concluded that age at the time of procedure was a significant risk factor for failed probing.

CONCLUSION: With the present study we conclude that, conservative management by nasolacrimal duct massaging of cases with congenital nasolacrimal duct obstruction has good results provided if started in early infancy. Proper education of the parents and understanding of the massaging process with regular follow up is must. As the age advances there are less chances of nasolacrimal duct massaging giving satisfactory results. Infant will have to be taken up for probing, which again has poor results as age advances.

\section{REFERENCES:}

1. Rajat Maheshwari ;Management of Congenital Nasolacrimal duct Obstruction; Journal of the Bombay Ophthalmologists' Association 2005 ,Vol. 14 No. 1. 44-47

2. Ballard EA.Excessive tearing in infancy and early childhood: the role and treatment of congenital nasolacrimal duct obstruction. Postgrad Med 2000; 107:149-54

3. Crigler LW. The treatment of congenital dacryocystitis. JAMA 1923, 81: 23-24. 
4. Price HW. Dacryostenosis. J Pediatr 1947, 30: 302-305.

5. Allen JH. External diseases of the eye. In: The Pediatrician's Ophthalmology. Eds Liebman SD, Gellis SS. Saint Lous, CV Mosby Co, 1966, pp 89-90.

6. Ipek E, Esin K, Amac K, Mustafa G, Candan A. Morphological and morphometric evaluation of lacrimal groove. Anatomical Science International. December 2007;82(4):207-10.

7. Maheshwari R, Maheshwari S.Late probing for congenital nasolacrimal duct obstruction .JCPSP 2007, Vol. 17 (1): 41-43

8. Pollard ZF. Tear duct obstruction in children. Clin Pediatr 1979, 18: 487-490.

9. Newels ophthalmology; principles and concepts $7^{\text {th }}$ ed .p250

10. Peterson RA, Robb RM. The natural course of congenital obstruction of the nasolacrimal duct. J Pediatr Ophthalmol Strabismus 1978, 15: 246-250.

11. D. ShivpuriA. Puri Congenital Nasolacrimal DuctObstruction: The ProperTechnique of Massage;Indian paediatrics ; vol 31 march 1994;337-340

12. Daniel MA, Jakobiec FA. Principles and Practice of Ophthalmology, Clinical Practice. WB Saunders, Philadelphia. 1994: 2812-20.

13. Nazullah Khan, Mohammad Naeem Khan, Sanaullah Jan, Shad Mohammad, Congenital Nasolacrimal Duct Obstruction: Presentation and Mangement; Pak J Ophthalmol 2006, Vol. 22 No. 2:,74-78

14. Halipota FM, Dahri GR, Anjum N, et al. Results of lacrimal probing in infants and children. Pak J Ophthalmol. 2000; 6: 47-50.

15. Paediatric Investigator Eye Disease Group; Resolution of congenital nasolacrimal duct Obstruction With Nonsurgical Management ;Arch Ophthalmol. 2012;130(6):730-734.

16. . Kenneth L. P, James A. K. Treatment of Congenital Nasolacrimal duct Obstruction. Ophthalmology Clinics of North America 1991; Vol 4, No 1, 201 - 209.

17. Kapadia MK, Freitag SK\&Woog JJ (2006): Evaluation and management of congenital nasolacrimal duct obstruction. Otolaryngol Clin North Am39: 959-977.

18. Yasuhiro Takahashi,1 Hirohiko Kakizaki,2 Weng 0. Chan3 and Dinesh Selva3; Management of congenital nasolacrimal duct obstruction Acta Ophthalmol. 2010: 88: 506-513

19. Qasem Hammory (MD-Ophthalmology), Hussein A Bataineh (MD-Pediatrics), Zheer Nusier (MDPediatrics). Congenital Nasolacrimal Duct Obstruction at Prince Rashed Hospital, Irbid, Jordan ; Sudanese journal of public health;October 2008,vol 3( 4);167169.

TABLE NO 1 . VARIABLES

\begin{tabular}{|l|l|}
\hline MEAN AGE AT PRESENTATION & 2 MONTHS 27 DAYS (87.12DAYS) \pm 41.147 SD \\
\hline MEDIAN AGE & 3 MONTHS ,5 DAYS (95 DAYS) \\
\hline MODE OF AGE & 3MONTHS ,25 DAYS (115DAYS) \\
\hline
\end{tabular}

TABLE NO.2 PRESENTING COMPLAINTS

\begin{tabular}{|c|c|c|}
\hline SYMPTOMS & $\mathbf{N}=\mathbf{5 7}$ & $\mathbf{\%}$ \\
\hline EPIPHORA & 13 & 22.80 \\
\hline MUCOID DISCHARHE & 20 & 35.08 \\
\hline MUCOPURULENT DISCHARGE & 24 & 42.10 \\
\hline
\end{tabular}




\section{ORIGINAL ARTICLE}

TABLE NO. 3 RESULTS OF NASO LACRIMAL DUCT MASSAGING AT THE END OF 16 WEEKS.

\begin{tabular}{|l|c|c|}
\hline & CURED & \% \\
\hline 4 WEEKS & 1 & 1.75 \\
\hline 6WEEKS & 5 & 8.77 \\
\hline 8 WEEKS & 15 & 26.31 \\
\hline 12WEEKS & 21 & 36.84 \\
\hline 16 WEEKS & 8 & 14.03 \\
\hline TOTAL & 50 & 87.71 \\
\hline
\end{tabular}

TABLE NO.4 RESULTS OF PROBING

\begin{tabular}{|l|c|}
\hline & No. Of Cases \\
\hline $\mathbf{1}^{\text {st }}$ probing (Cured) & 3 \\
\hline $\mathbf{2}^{\text {nd }}$ probing (Cured) & 2 \\
\hline Referral (Not cured) & 2 \\
\hline
\end{tabular}

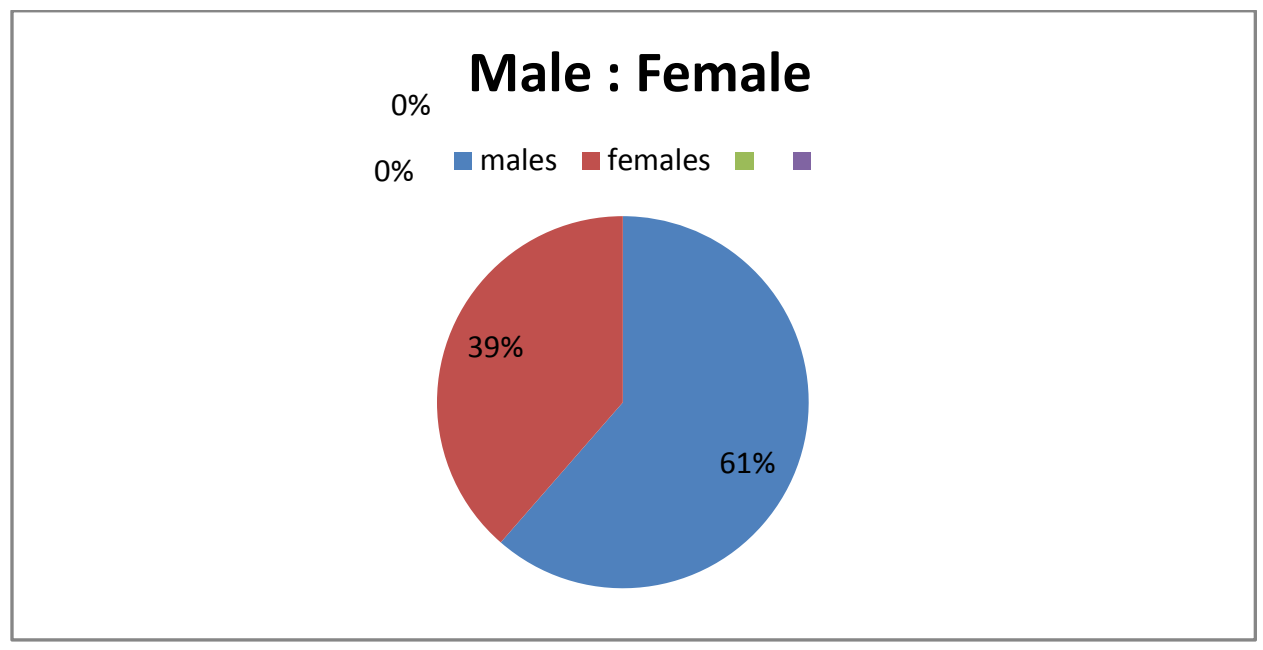

FIGURE. 1 GENDER DISTRIBUTION

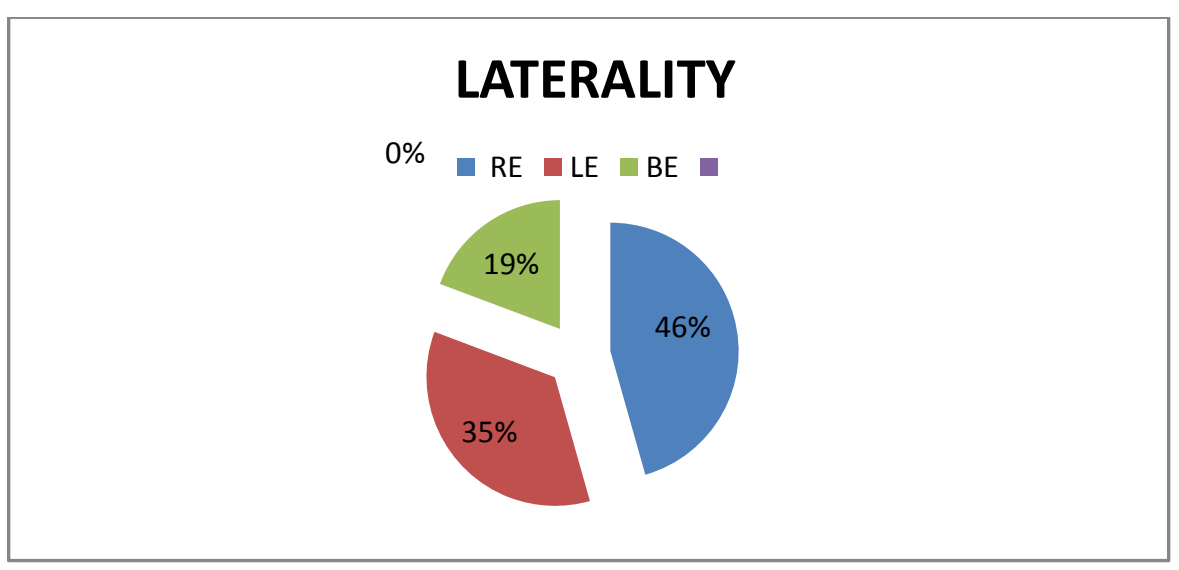

FIGURE. 2: LATERALITY 


\section{ORIGINAL ARTICLE}

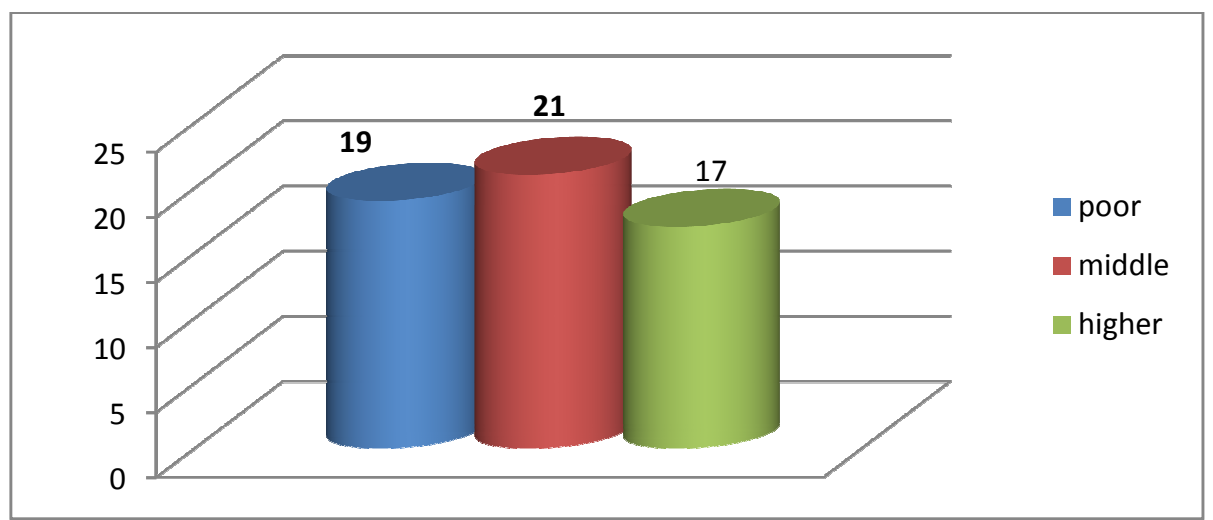

FIGURE. 3 SOCIOECONOMIC STRATA

\section{REFERRAL PATTERN}

u paediatrician $\square$ self $\square$ medical practitioner

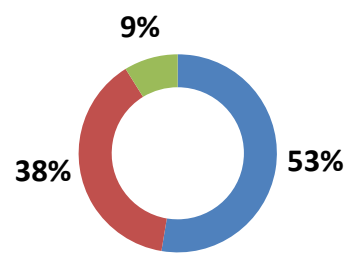

FIGURE. 4. REFERRAL PATTERN 